\title{
Research on Application of Bakri Balloon Tamponade in Treatment of 169 Cases of Postpartum Hemorrhage
}

\section{Hui Yang}

Huazhong University of Science and Technology

\section{Mei Dong Cao}

Huazhong University of Science and Technology

yun zhao ( zhao020060@163.com)

maternal and child health hospital of hubei province, affiliated hospital of tongji medical college, huazhong university of science and technology https://orcid.org/0000-0002-2323-2926

\section{Qiang Guo Sun}

Huazhong University of Science and Technology

\section{Yao Cheng}

Huazhong University of Science and Technology

\section{Research article}

Keywords: Bakri balloon, placental adhesion, placenta implantation, postpartum hemorrhage

Posted Date: January 16th, 2021

DOI: https://doi.org/10.21203/rs.3.rs-146926/v1

License: (c) (i) This work is licensed under a Creative Commons Attribution 4.0 International License. Read Full License 


\section{Abstract}

Background: To acquire a better understanding of application effect, advantages and disadvantages of Bakri balloon tamponade in treatment of postpartum hemorrhage, and explore the appropriate pathological occasion and optimal timing for placing Bakri balloon.

Methods: A retrospective study which used Bakri balloon for postpartum hemorrhage was conducted from January 1 , 2016 to December 31, 2019 in our hospital .

Results: There were 169 patients who treated with Bakri balloon tamponade, no detachment occurred after Bakri balloon cervical forceps clipped with toothless oval forceps. There were 148 cases of successful balloon tamponade hemostasis, accounting for $87.6 \% \bigotimes$ and 21 failure cases, accounting for $12.4 \%$. The failure rate of balloon tamponade hemostasis significantly increased in the case of over $1500 \mathrm{ml}$ bleeding. In the failure group, placental adhesion and accreta accounted for $57.1 \%(12 / 21)$, and placental implantation was found an important factor causing balloon tamponade hemostasis failure.

Conclusion: Cervical forceps clipped with toothless oval forceps can effectively prevent the failure of hemostasis due to balloon prolapse. When postpartum hemorrhage reaches $1500 \mathrm{ml}$ and/or placenta accreta is carried out, failure rate of balloon tamponade hemostasis will increase significantly. Nevertheless, it could be used as a temporary measure for less hemorrhage volume and more time toward further treatment.

\section{Background}

Postpartum hemorrhage (PPH) is a serious complication during childbirth as well as one of the leading causes of maternal morbidity and mortality all over the world ${ }^{[1,2]}$. PPH accounts for $30.8 \%$ and $33.9 \%$ of all direct obstetric mortality in Africa and Asia, respectively ${ }^{[2]}$. Globally speaking, these rates are equivalent to approximately 140,000 deaths per year or one death every four minutes ${ }^{[3]}$. Therefore, correct and proactive treatment of PPH is the key to reduce maternal mortality. Currently, there are various treatment methods for postpartum hemorrhage, including uterine massage, uterotonic agents injection, intrauterine packing with gauze, uterine B Lynch suture, lower uterine segment constriction suture, uterine artery ligation, internal iliac artery ligation, uterine artery embolisation, hysterectomy, etc. In this study, a retrospective analysis of postpartum hemorrhage cases treated by Bakri balloon in recent four years is carried out. The therapeutic effect, advantages and disadvantages of Bakri balloon are investigated, which provides theoretical basis for seeking appropriate pathological occasion and optimal timing for placing Bakri balloon and for developing a more reasonable and effective method for postpartum hemorrhage treatment.

\section{Materials And Methods}

A retrospective analysis involving 169 cases of postpartum hemorrhage treated by Bakri balloon during delivery in our hospital from January 1, 2016 to December 31, 2019 was carried out. The study was approved by the Ethics Committee of Maternal and Child Health Hospital of Hubei Province. Before placing Bakri balloons, all selected cases underwent normal hemostatic measures such as uterotonic agents injection (including Hemabate, Carbetocin, etc.), uterine massage and/or various sutures for obvious bleeding part in cesarean section (including multiple " 8 " sutures, uterine B Lynch sutures, lower uterine segment constriction suture, ascending uterine artery ligation). If these conventional hemostatic measures failed to control bleeding, then Bakri balloon tamponade was considered. 
Bakri balloons, which is made by COOK, USA, can be used to monitor the continued bleeding in real time by observing the uterine drainage fluid in the drainage tube. Bakri balloon placement method can be basically described as follows:

1. Transvaginal placement after vaginal delivery or cesarean section: with the aid of ultrasound guidance,Bakri balloon was inserted directly into the uterine cavity through the vagina and the cervix, with the top of the balloon against the fundus of the uterus, and then $300-500 \mathrm{ml}$ of saline was injected.

2. Place the Bakri balloon through a surgical incision during cesarean section: the valve of the Bakri injection port was removed, and Bakri was placed through a uterine incision and the catheter was inserted through the endocervical orifice. After that, the assistant pulled the drainage tube through the vagina at the outer cervical orifice and removed it through the vagina. The valve of the injection port was reinstalled and injected with 300$500 \mathrm{ml}$ of normal saline.

To avoid balloon slippage, one to four toothless oval forceps were used to fit the upper and lower lip of the cervix to the clamps at three and nine o'clock (depth to the fornix on both sides) before the balloon was placed (transvaginally placed) or before water injection (through the surgical incision), leaving only a gap that can accommodate the width of the balloon catheter which was shown in Fig. 1. (It is worth noting that such procedure can be omitted for those with tight and tough cervix.) After the clamping was completed, the decision should be made whether to place sterile gauze in the posterior vault of the vagina or not. The average indwelling time of the balloon was $8 \sim 48 \mathrm{~h}$. The balloon fluid was released in different times according to the hemostatic effect. First the toothless oval forceps are taken, and finally the balloon is removed.

The evaluation of Bakri balloon hemostasis is divided into effective and in effective. When the uterine drainage fluid $<100 \mathrm{ml} / \mathrm{h}$ is observed, the color is dark red, the bleeding gradually is decreased or stopped, and the uterine contraction is normal, the balloon hemostasis is considered effective. If the uterine cavity drainage fluid is $\geq$ $100 \mathrm{ml} / \mathrm{h}$, the color is bright red, the uterine contraction is poor, or the intractable uterine contraction is weak, other measures should be adopted to treat it, etc. ${ }^{[4]}$, the effect of balloon hemostasis is evaluated as invalid. According to the above evaluation methods, the "effective" cases were categorized into the "success group" and the "ineffective" cases requiring other measures were categorized into the "failure group". All of the parameters were compared between the success group and the failure group.

The statistical analysis was performed using SPSS20.0 software. The measurement data of postpartum hemorrhage patients in the two groups were expressed as ${ }^{\prime} x \pm s$, and T- test was used for intergroup comparison. The counting data were expressed as \%, and the Fisher's exact test was used for those who did not meet $\chi^{2}$ test condition when the sample size was small. If $P$ value $<0.05$, differences of various observation indicators between the two groups were considered statistically significant.

\section{Results}

In this research, the selected 169 patients in which 11 cases of labor induction due to fatal malfunction were included aged from 18 to 42 years old, with gestational weeks from $22^{+2}$ to $41^{+4}$ weeks. The sample size included 119 cases of primipara and 50 cases of multipara as well as 139 cases of vaginal delivery and 30 cases of cesarean section, and eight successful cases of Bakri balloon placement through surgical incision during intrauterine delivery. The cases of postpartum hemorrhage due to uterine contractions atony account for 70 , with 4 cases of blood coagulation dysfunction-one for acute leukemia, two for amniotic fluid embolism and the rest for acute fatty liver-included. The remaining 99 cases, along with contractions atony, were associated with the placentas, divided into four cases of 
placental abruption, 68 cases of placenta adhesion, five cases of placenta previa (two coupled with placenta adhesion), and 22 cases of placenta increta (three cases of placenta previa included).The amount of postpartum bleeding was estimated by a combination of volume method and weighing method. The total amount of bleeding was $700 \sim 4000 \mathrm{ml}$, and the volume of red blood cells was $0 \sim 17 \mathrm{u}$.

148 successful cases and 21 failure ones were presented in the application of Bakri balloon hemostasis. The balloon detachment was performed in one vaginal delivery of above 21 cases on account of the failed clipping of cervix with toothless oval forceps. The use of the oval non-toothed forceps to clamp the cervix with the balloon in-situ found no cervical necrosis. Bilateral uterine/internal iliac artery interventional embolization was adopted for all failed hemostasis cases without a single case of hysterectomy or maternal death.

Statistically, there was no significant difference in maternal age, gestational age, number of pregnancies, history of abortion, history of cesarean section, history of uterine fibroids / adenomyomas, number of pregnancies (single/multiple births), mode of delivery and birth weight of newborns between the two groups $(P>0.05)$. However, if there were other uterine cavity operation history (including decomposition of endometrial adhesion, excision of uterine septum, diagnostic uterine curettage, etc.) other than abortion, the length of hospital stay after delivery and the cost would be statistically significant $(P<0.05)$. Comparison of the basic information of Bakri balloon success group and failure group are shown in Table 1.

There was no significant difference in balloon infusion volume between the successful group and the failure group. However, there was significant difference in postpartum blood volume, transfused red blood cells and balloon dwelling time between two groups $(P<0.05)$ as shown in Table 2 , which indicated significant increase of failure rate of balloon hemostasis in the case of over $1500 \mathrm{ml}$ postpartum hemorrhage. Additionally, the balloon was removed for application of other hemostasis methods due to the failure of balloon hemostasis, which brought out the significantly shorter balloon dwelling time.

Uterine atony is the leading cause to PPH. The placenta-related factor contributed to the top risk of Bakri balloon hemostasis for postpartum hemorrhage. Of the 21 failure cases, 15 ones were associated to placenta factors and mostly accompanied with placenta adhesion and accrete, and the rate of placenta implantation reached $57.1 \%$ (12/21). The details are shown in Table 3.

\section{Discussion}

Before placing the balloon, one to four toothless oval forceps were usually used to clamp the upper and lower lips of the cervix at three o'clock and nine o'clock ( deep to both sides of the fornix) according to the cervical condition, leaving the gap being just equivalent to the width of the balloon catheter (it is worth noting that such procedure should not be applied for those with tight and tough cervix). This approach can prevent balloon from slipping in an effective way. Furthermore, The application of oval forceps to cervix can not merely block part of the blood vessels distributed in uterus for supply, but also facilitate uterine contraction through reflective stimulation so as to reduce colporrhagia.

Of all 169 cases of Bakri balloon hemostasis, 148 cases were successful, with a success rate of 87.6\% (148/169). Separately, the success rate of balloon hemostasis presented $87.1 \%(121 / 139)$ in 139 vaginal delivery cases including 11 abortion cases on malformation and 6 cases of forceps delivery. The success rate presented $90.0 \%$ $(27 / 30)$ in 30 massive postpartum hemorrhage cases (three failures out of 22 cases of transvaginal balloon placement after cesarean section and eight success cases of balloon placement through surgical incision during 
cesarean section. There was no correlation between the Bakri balloon infused volume and the hemostatic effect. The balloon infused volume is generally determined based on the cause of bleeding, the use (or not use) of uterine binding suture, and the results of balloon tamponade test ${ }^{[5]}$. Bakri balloons have been widely recommended for the treatment of postpartum hemorrhage. Most studies consider its effectiveness to be more than $90 \%$, but some scholars believe that the effectiveness of Bakri balloons for treating PPH is questioned. A retrospective study by Olsen Richelle et $\mathrm{al}^{[6]}$. found that the success rate of Bakri balloon hemostasis was around $67.57 \%$, which was not so effective as previously announced. However, the success rate of Bakri balloon hemostasis in this study was close to $90 \%$, which basically supports the previous reports of most domestic and foreign scholars ${ }^{[7-9]}$.

Many domestic and foreign studies have suggested that once PPH is diagnosed, Bakri balloon hemostasis should be used in a timely manner when first-line hemostatic drugs and methods cannot effectively control bleeding ${ }^{[10]}$. This study found that the hemostasis effect of Bakri balloons was remarkable when the postpartum bleeding volume was less than $1500 \mathrm{ml}$, but the failure rate would increase significantly when the bleeding volume reached $1500 \mathrm{ml}$. Therefore, once the bleeding exceeds $1500 \mathrm{ml}$, other hemostatic methods shall be considered.

In this research, Bakri balloons were successfully placed through surgical incision in 8 patients who had undergone cesarean section. Bakri balloons are mainly used for those with poor uterine contraction, those with diffuse bleeding in the uterine cavity, and those who had low compliance with suture. With the improvement of surgical suture skills, hemostasis can be achieved in most cases during cesarean section by means of first-line hemostatic drugs and various suture techniques. In the case of heavy intraoperative bleeding and difficulty in suture, the adoption of balloons can play a role in temporarily pressing hemostasis and reducing the amount of bleeding, so as to win time for the further hemostatic measures such as uterine/internal iliac artery interventional embolization therapy, thus effectively reducing the rate of uterine resection. Relevant studies from home and abroad have indicated that prophylactic adoption of Bakri balloons can greatly reduce postpartum blood loss and hysterectomy rate ${ }^{[11-12]}$. Some scholars have advocated the prophylactic application of Bakri balloons in cesarean section of placenta previa ${ }^{[13]}$. Rapid diagnosis or prognosis of postpartum hemorrhage combined with early use of Bakri balloon is more effective in controlling postpartum hemorrhage ${ }^{[14]}$. As the least invasive and fastest approach, Balloon tamponade is considered as the first attempt of conservative surgical method for $\mathrm{PPH}$.

In this study, it was found that postpartum hemorrhage was mainly related to uterine contraction weakness, and placental factors accounted for 58.6\% (99/169), including placenta previa, placental abruption, placental adhesion and placental implantation. Of the 21 cases of failed balloon hemostasis, 15 cases were related to placental factors, including 11 cases of placental adhesion with implantation, accounting for $52.4 \%(11 / 21)$, suggesting that placental implantation was an important factor leading to Bakri balloon hemostasis failure. This is probably due to that retained placenta leads to uneven inner wall of uterine cavity and irregular shape, which is against the effective fitting of balloon and uterine cavity, thus imposing a negative influence on the hemostatic effect of balloon compression. Furthermore, the residual placenta continued to bleed, resulting in balloon hemostasis failure. Therefore, Bakri balloons may not be the optimal treatment for hemostasis in case of placental implantation, especially in large areas, or even placental penetration. Soyama $\mathrm{H}^{[15]}$ pointed out that invasive treatment is an unavoidable method for patients with placental retention to stop bleeding. If continuous bleeding in the intrauterine drainage tube is caused by placenta retention, further hemostasis should be performed immediately ${ }^{[11]}$. After a series of basic treatments such as removal of placenta tissue and suture of bleeding site, if the balloon is placed to stop bleeding, the bleeding situation in the catheter should be closely observed, and the interventional embolization or hysterectomy should be prepared at any time. Bakri balloons have insignificant effect on the patients with placental penetration. However, prior to more invasive procedures, pre-positioned Bakri balloons may be a good choice for placental implantation / 
penetration $^{[16]}$. The Bakri balloon can play a temporary role in compressing hemostasis, and can effectively control the rapidly opened blood sinus. Although it may fail as a treatment, it can slow bleeding and win time for further invasive procedure such as uterine/internal iliac artery embolization or hysterectomy and for safely transferring the patient to a superior medical treatment center ${ }^{[11]}$.

\section{Conclusions}

Bakri balloons have been proven to be an effective treatment for postpartum hemorrhage caused by weak uterine contraction, and cervical forceps with toothless oval forceps can effectively prevent hemostasis failure caused by balloon prolapse. When postpartum haemorrhage amount is more than $1500 \mathrm{ml}$, the hemostatic effect of Bakri balloon will be greatly reduced. In the case that invasive surgical intervention may be the only option for controlling postpartum hemorrhage, the application of balloon can serve as a temporary measure to lower blood loss, thus avoiding fatal hemorrhage before surgical intervention.

\section{Limitations}

First, this study was a retrospective study in which the data were only collected from patients' medical records, and cases of postpartum haemorrhage who were not treated with the Bakri balloon not used as a control group in this study.

Second, there may be acknowledged possible selection bias as patients were allocated to each group according to baseline cervical condition.

\section{Abbreviations}

$\mathrm{PPH}$

postpartum hemorrhage

\section{Declarations}

\section{Acknowledgments}

We thank the staff in the medical record room for their help in inquiring about the patient's information. We also thank the Ministry of Science and Education of Maternal and Child Health Hospital of Hubei Province for the critical reading of the manuscript.

\section{Author's contributions}

All authors had full access to all the data in the study and take responsibility for the integrity of the data and the accuracy of the data analysis. Each of us was involved in the writing and revision of the manuscript. All authors read and approved the final version. Hui Yang, Dongmei Cao, Yun Zhao and Guoqiang Sun were responsible for study concept and design. Hui Yang, Dongmei Cao were responsible for date collection. Yao Cheng was responsible for data analysis. Hui Yang and Dongmei Cao were responsible for writing-original draft. Yun Zhao and Guoqiang Sun were responsible for writing-review and editing. 


\section{Funding}

This work was supported by the Foundation from Health and Family Planning Commission of Hubei Province (No: WJ2018h0133), Innovative Research Team of Hubei Provincial Science and Technology Department (No: 2019CFA033) and Wuhan Science and Technology Planning Foundation (No: 2020020601012215). All of the foundations agreed to fund obstetric researchers for data analysis, English editing and other costs related to the dissemination of the study.

\section{Availability of data and materials}

Access to the qualitative data will be given upon request to the corresponding author after taking any necessary precautions to safeguard participants' privacy and confidentiality.

\section{Ethics approval and consent to participate}

The study conformed to the guidelines explained in the Declaration of Helsinki and was approved by the Ethics Committee of Maternal and Child Health Hospital of Hubei Province ([2020] IEC(LW029)). All included women signed written informed consent for therapeutic procedures and for the publication of those reports.

\section{Consent for publication}

Not applicable.

\section{Competing interests}

The author declares that they have no competing interests.

\section{Author details}

Department of Obstetrics, Maternal and Child Health Hospital of Hubei Province, Tongji Medical College, Huazhong University of Science and Technology, No. 745, Wuluo Road, Hongshan District, Wuhan 430070, China.

\section{References}

1. Carroli G, Cuesta C, Abalos E, Gülmezoglu AM. Epidemiology of postpartum haemorrhage: a systematic review. Best Pract Res Clin Obstet Gynaecol. 2008;22(6):999-1012. DOl:10.1016/j.bpobgyn.2008.08.004.

2. Khan KS, Wojdyla D, Say L, Gülmezoglu AM, Van Look PF. WHO analysis of causes of maternal death: a systematic review. Lancet. 2006;367(9516):1066-74. DOI:10.1016/s0140-6736(06)68397-9.

3. AbouZahr C. Global burden of maternal death and disability. Br Med Bull. 2003;67:1-11. DOl:10.1093/bmb/ldg015.

4. Cho HY, Park YW, Kim YH, et al. Efficacy of Intrauterine Bakri Balloon Tamponade in Cesarean Section for Placenta Previa Patients. PLoS One. 2015;10(8):e0134282. DOI:10.1371/journal.pone.0134282. 
5. Tang F, Zhao Y, Sun GQ,et al. Effect of Bakri balloon intrauterine tamponade for intractable postpartum hemorrhage. Chinese Journal of Perinatal Medicine. 2017;20(12):891-4. DOI:10.3760/cma.j.issn.10079408.2017.12.010.

6. Olsen R, Reisner DP, Benedetti TJ, et al. Bakri balloon effectiveness for postpartum hemorrhage: a "real world experience". The journal of maternal-fetal neonatal medicine. 2013;26(17):1720-3.

DOI:10.3109/14767058.2013.796354.

7. Gao Y, Wang Z, Zhang J, et al. Efficacy and safety of intrauterine Bakri balloon tamponade in the treatment of postpartum hemorrhage: a multicenter analysis of 109 cases. Chinese Journal of Obstetrics Gynecology. 2014;49(9):670-5. DOI:10.3760/cma.j.issn.0529-567x.2014.09.007.

8. Condous GS, Arukumaran S. Medical and conservative surgical management of postpartum hemonhage. $\mathrm{Br} \mathrm{J}$ Obstet Gynaecol Can. 2003;25(11):931-6. DOI:10.1016/s1701-2163(16)30241-9.

9. Kong MC, To WW. Balloon tamponade for postpartum haemorrhage: case series and literature review. Hong Kong Medical Journal. 2013;19(6):484-90. DOl:10.12809/hkmj133873.

10. Tunçalp O, Souza JP, Gülmezoglu M. New WHO recommendations on prevention and treatment of postpartum hemorrhage. Int J Gynaecol Obstet. 2013;123(3):254-6. DOI:10.1016/j.ijgo.2013.06.024.

11. Gronvall M, Tikkanen M, Tallberg E, Paavonen J, Stefanovic V. Use of Bakri balloon tamponade in the treatment of postpartum hemorrhage: a series of 50 cases from a tertiary teaching hosipital. Acta obstetricia et gynecologica Scandinavica. 2013;92(4):433-8. DOl:10.1111/j.1600-0412.2012.01531.x.

12. Beckmann MM, Chaplin J. Bakri balloon during cesarean delivery for placenta previa. International Journal of Gynecology Obstetrics. 2014;124:118-22. DOI:10.1016/j.ijgo.2013.08.010.

13. Cui J, Li P, Zhang Y, Fan J. Application of Bakri uterine stuffing balloon catheter in placenta previa cesarean section. Journal of Sun Yat-sen University (Medical Sciences). 2014;35(4):565-9.

14. Wang D, Xu S, Qiu X, Zhu C, LI Z. Early usage of Bakri postpartum balloon in the management of postpartum hemorrhage: a large prospective, observational multicenter clinical study in South China. Journal of perinatal medicine. 2018;46(6):649-56. DOI:10.1515/jpm-2017-0249.

15. Soyama $H$, Miyamoto $M$, Ishibashi $H$, et al. Analysis of prophylactic Bakri balloon tamponade failure in patients with placenta previa. Taiwan J Obstet Gynecol. 2019;58(1):159-63. DOl:10.1016/j.tjog.2018.11.029.

16. Zeng C, Yang M, Ding Y, et al. Preoperative infrarenal abdominal aorta balloon catheter occlusion combined with Bakri tamponade reduced maternal morbidity of placenta increta /percreta. Medicine, 2017, 96(38): DOI: e8114. 10.1097/MD.0000000000008114.

\section{Tables}

Table1

Comparison of the basic information of Bakri balloon success group and failure group 


\begin{tabular}{|c|c|c|c|c|}
\hline Basic information & $\begin{array}{l}\text { Success group } \\
(n, \%)\end{array}$ & $\begin{array}{l}\text { Failure group } \\
(n, \%)\end{array}$ & $t / x^{2}$ & $\mathbf{P}$ \\
\hline Maternal age $(y \rrbracket$ & & & 0.3424 & 0.5585 \\
\hline$\geq 35$ & 21 (14.19\%) & 4 (19.05\%) & & \\
\hline$<35$ & $127(85.81 \%)$ & $17(80.95 \%)$ & & \\
\hline Gestational age at childbirth & & & 0.0318 & 0.8584 \\
\hline$\geq 37$ & $132(89.19)$ & 19 (90.48) & & \\
\hline$<37$ & $16(10.81)$ & $2(9.52)$ & & \\
\hline Pregnancy times & & & 0.8378 & 0.3600 \\
\hline 1 & $65(90.28)$ & $7(9.72)$ & & \\
\hline$\geq 2$ & $83(85.57)$ & $14(14.43)$ & & \\
\hline Abortion history & & & 1.2208 & 0.2692 \\
\hline Yes & $72(48.98)$ & $13(61.9)$ & & \\
\hline No & 75 (51.02) & $8(38.1)$ & & \\
\hline Other intrauterine operation history & & & 9.5754 & 0.002 \\
\hline Yes & $14(9.46)$ & 7 (33.33) & & \\
\hline No & $134(90.54)$ & $14(66.67)$ & & \\
\hline Parity & & & 0.1607 & 0.6885 \\
\hline 1 & $105(70.95)$ & $14(66.67)$ & & \\
\hline$\geq 2$ & $43(29.05)$ & $7(33.33)$ & & \\
\hline Cesarean delivery history & & & - & 0.6967 \\
\hline Yes & $14(9.46)$ & $1(4.76)$ & & \\
\hline No & $134(90.54)$ & $20(95.24)$ & & \\
\hline Mode of dilivery & & & 0.1961 & 0.6579 \\
\hline Vaginal delivery & $121(81.76)$ & $18(85.71)$ & & \\
\hline Cesarean delivery & 27 (18.24) & $3(14.29)$ & & \\
\hline Newborn weight (g) & & & - & 0.8081 \\
\hline$<2500$ & $11(7.43)$ & $1(4.76)$ & & \\
\hline 2500-3999 & $121(81.76)$ & $19(90.48)$ & & \\
\hline$>3999$ & $16(10.81)$ & $1(4.76)$ & & \\
\hline Days of hospital stay after delivery (d) & 4.5486ه1.4134囚 & 5.4762ه1.6006ه & 2.76 & 0.0064 \\
\hline Cost (RMB) & 21184.2囚43428.7】 & 35028.4『6211.7】 & 3.54 & 0.0005 \\
\hline
\end{tabular}


Student's test, Chi- square test and the Fisher's exact test were used

Table 2

Comparison of hemostatic effects between success and failure group

\begin{tabular}{|c|c|c|c|c|c|c|c|}
\hline \multirow[t]{2}{*}{ Groups } & \multirow{2}{*}{$\begin{array}{l}\text { Number } \\
\text { of } \\
\text { cases }\end{array}$} & \multicolumn{2}{|c|}{$\begin{array}{l}\text { Total blood } \\
\text { loss(ml)(n】\%) }\end{array}$} & \multirow{2}{*}{$\begin{array}{l}\text { Total blood } \\
\text { loss(ml) } \\
(X \pm S)\end{array}$} & \multirow{2}{*}{$\begin{array}{l}\text { Red blood cell } \\
\text { infusion(u) } \\
(X \pm S)\end{array}$} & \multirow{2}{*}{$\begin{array}{l}\text { Balloon } \\
\text { infused } \\
\text { volume(ml) } \\
(X \pm S)\end{array}$} & \multirow{2}{*}{$\begin{array}{l}\text { Indwelling } \\
\text { time(hr) } \\
(X \pm S)\end{array}$} \\
\hline & & $<1500$ & $\geq 1500$ & & & & \\
\hline $\begin{array}{l}\text { Succes } \\
\text { group }\end{array}$ & 148 & $\begin{array}{l}121 \\
(81.76)\end{array}$ & $\begin{array}{l}27 \\
(18.24)\end{array}$ & $1114.9 \pm 368.9$ & $2.6351 \pm 1.9234$ & $429.4 \pm 63.4685$ & $19.598 \pm 6.4097$ \\
\hline $\begin{array}{l}\text { Failure } \\
\text { group }\end{array}$ & 21 & $\begin{array}{l}6 \\
\bigotimes 28.57 \rrbracket\end{array}$ & $\begin{array}{l}15 \\
(71.43)\end{array}$ & $1742.9 \pm 630.5$ & $6.2143 \pm 3.5481$ & $448.9 \pm 61.0582$ & $8.3444 \pm 5.5688$ \\
\hline$t / x^{2}$ & & 27.6899 & & -4.46 & -4.53 & 1.23 & $<0.0001$ \\
\hline $\mathbf{P}$ & & $<0.0001$ & & 0.0002 & 0.0002 & 0.2206 & $<0.0001$ \\
\hline
\end{tabular}

Student's test and the Fisher's exact test were used

Table 3

Clinical data of Bakri balloon failure cases

\begin{tabular}{|llll|}
\hline Placental factor & Other high risk factors & Cause of bleeding & $\begin{array}{c}\text { Cause } \\
\text { of } \\
\text { failure }\end{array}$ \\
\hline No placental factor $(n=6)$ & $\begin{array}{l}\text { Preeclampsia }(n=4) \\
\text { Giant }(n=1)\end{array}$ & Uterine atony & $\begin{array}{l}\text { Uterine } \\
\text { atony }\end{array}$ \\
\hline placental adhesions $(n=3)$ & Hypertension $(n=1)$ & $\begin{array}{l}\text { Exfoliation of placenta and } \\
\text { Uterine atony }\end{array}$ & $\begin{array}{l}\text { Uterine } \\
\text { atony }\end{array}$ \\
\hline $\begin{array}{l}\text { placental adhesions and } \\
\text { accreta }(n=10)\end{array}$ & $\begin{array}{l}\text { Uterine operation history }(n=1) \\
\text { intrauterine operation history }(n=6), \\
(n=1)\end{array}$ & $\begin{array}{l}\text { Placenta accreta } \\
\text { Exfoling with severe preeclampsia }\end{array}$ & $\begin{array}{l}\text { Placenta } \\
\text { accreta }\end{array}$ \\
\hline $\begin{array}{l}\text { Placenta previa with } \\
\text { placenta adhesion and } \\
\text { accreta }(n=2)\end{array}$ & $\begin{array}{l}\text { Uterine atony } \\
\text { iadacenta and }\end{array}$ \\
\hline
\end{tabular}

\section{Figures}




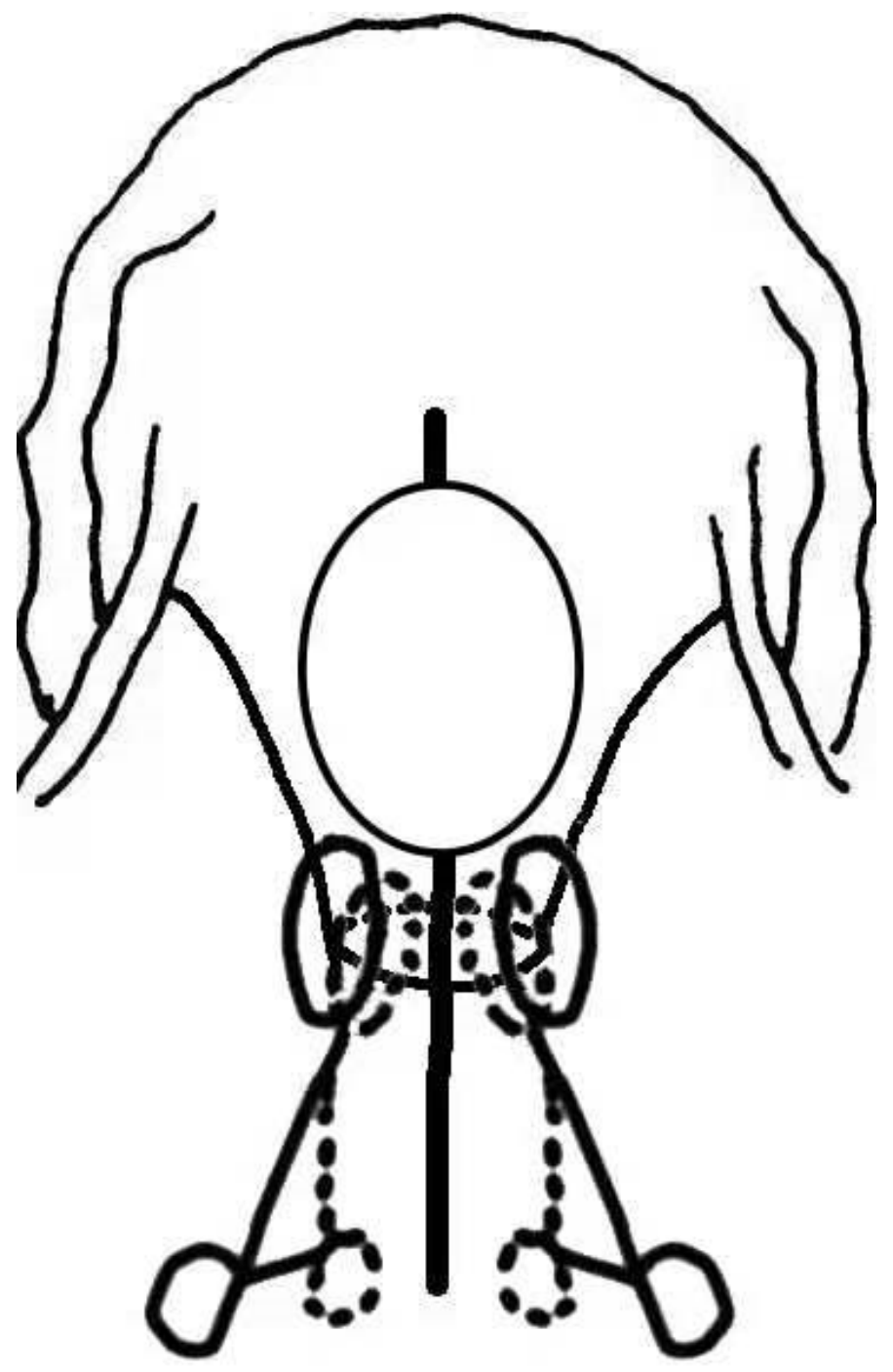

Figure 1

It is worth noting that such procedure can be omitted for those with tight and tough cervix. 